\title{
No evidence for $\beta$ cell neogenesis in murine adult pancreas
}

\author{
Xiangwei Xiao, Zean Chen, Chiyo Shiota, Krishna Prasadan, Ping Guo, \\ Yousef El-Gohary, Jose Paredes, Carey Welsh, John Wiersch, and George K. Gittes
}

Division of Pediatric Surgery, Children's Hospital of Pittsburgh, University of Pittsburgh School of Medicine, Pittsburgh, Pennsylvania, USA.

\begin{abstract}
Whether facultative $\beta$ cell progenitors exist in the adult pancreas is a major unsolved question. To date, lineage-tracing studies have provided conflicting results. To track $\beta$ cell neogenesis in vivo, we generated transgenic mice that transiently coexpress mTomato and GFP in a time-sensitive, nonconditional Cre-mediated manner, so that insulin-producing cells express GFP under control of the insulin promoter, while all other cells express mTomato (INS ${ }^{\mathrm{Cre}} \mathrm{mTmG}$ mice). Newly differentiated $\beta$ cells were detected by flow cytometry and fluorescence microscopy, taking advantage of their transient coexpression of GFP and mTomato fluorescent proteins. We found that $\beta$ cell neogenesis predominantly occurs during embryogenesis, decreases dramatically shortly after birth, and is completely absent in adults across various models of $\beta$ cell loss, $\beta$ cell growth and regeneration, and inflammation. Moreover, we demonstrated upregulation of neurogenin 3 (NGN3) in both proliferating ducts and preexisting $\beta$ cells in the ligated pancreatic tail after pancreatic ductal ligation. These results are consistent with some recent reports, but argue against the widely held belief that NGN3 marks cells undergoing endocrine neogenesis in the pancreas. Our data suggest that $\beta$ cell neogenesis in the adult pancreas occurs rarely, if ever, under either normal or pathological conditions.
\end{abstract}

\section{Introduction}

Despite some success with islet transplantation for the treatment of diabetes, the short supply of donor pancreata constitutes a formidable obstacle to the further development and clinical application of this therapy $(1,2)$. This shortage heightens the need for alternative sources of insulin-producing cells. Since mature $\beta$ cells have a very slow proliferation ratio (3), much effort has been made to identify adult $\beta$ cell progenitors. However, whether facultative $\beta$ cell progenitors exist in the adult pancreas is still a major unsolved question. Two major pancreatic cell types, duct cells and acinar cells, have been extensively studied for their potential to generate $\beta$ cells. Although some in vitro experiments have suggested that adult acinar cells can be converted into insulin-secreting $\beta$ cells under certain experimental conditions $(4,5)$, lineage-tracing experiments did not support this possibility in vivo (6). On the other hand, embryonic duct cells in the pancreatic trunk are direct precursors of transient neurogenin 3 -positive $\left(\mathrm{NGN3}^{+}\right)$cells, which give rise to all endocrine cell types, including $\beta$ cells during embryogenesis (7-17). Therefore, adult pancreatic ducts have also been suggested to harbor progenitors for insulin-producing $\beta$ cells (18). However, in 2004 an innovative genetic pulse-chase study showed that $\beta$ cell proliferation is the only pathway for $\beta$ cell expansion in adults (19), which was further strengthened by an elegant nongenetic lineage-tracing study based on serial thymidine analog labeling (20). This conclusion was later challenged by a report of NGN3 activation in ducts in the pancreatic ductal ligation (PDL) model, in which the authors showed that isolated $\mathrm{NGN}^{+}$cells differentiate into insulin-secreting $\beta$ cells after they were injected into NGN3 knockout embryonic pancreatic explants (21). Notably, lineage-tracing studies provided conflicting results later on. In one report, $\beta$ cells were found labeled after duct cell labeling, followed by PDL (22), while such a lineage was not found

Conflict of interest: The authors have declared that no conflict of interest exists. Citation for this article: J Clin Invest. 2013;123(5):2207-2217. doi:10.1172/JCI66323. in other studies (23-26). Meanwhile, doubts have arisen about the quality of the RIP-CreERT labeling system that was used in the genetic pulse-chase study (19, 27-29). Also, recent CreERT mice that have been used for lineage tracing have yet to be validated by follow-up work. Indeed, potential problems with using tamoxifen have been reported in some CreERT mice, involving either low, nonspecific, or inconsistent tamoxifen-induced labeling (30).

In the current study, we used a nonconditional Cre in a time-sensitive system, combining existing transgenic lines to generate insulin-promoter Cre and ROSA26-promoter-loxP-membrane-Tomato-loxP-membrane-GFP (INS ${ }^{\mathrm{Cr}} \mathrm{mTmG}$ ) compound mice. In these mice, all cells are Tomato ${ }^{+}\left(\mathrm{mT}^{+}\right)$, except for the insulin ${ }^{+}\left(\mathrm{INS}^{+}\right)$ cells and their progeny, which are $\mathrm{GFP}^{+}\left(\mathrm{mG}^{+}\right)$. However, when non- $\beta$ cells start to express the insulin promoter for the first time, there is a brief period (40-48 hours) during which the cells are still $\mathrm{mT}^{+}$but already express GFP, and hence appear yellow. This time window allows us to identify $\beta$ cells undergoing neogenesis using microscopy and, more objectively, FACS. This approach was used to examine possible $\beta$ cell neogenesis during development, significant $\beta$ cell loss, $\beta$ cell growth/regeneration, and in inflammation.

\section{Results}

Generation of INS ${ }^{\mathrm{Cre}} \mathrm{mTm} G$ mice for the detection of $\beta$ cell neogenesis. INSCremTmG compound mice were generated by crossing INS $^{\text {Cre }}$ (31) with mTmG mice (32). These mice express strong red fluorescence in all cells except for the $\mathrm{INS}^{+} \beta$ cells, whose floxed membrane-targeted Tomato $(\mathrm{mT})$ cassette is deleted, leading to constitutive expression of the membrane-targeted EGFP (mG) cassette located just downstream. Importantly, we found that $\mathrm{mG}$ is exclusively detected in $\beta$ cells (Supplemental Figure 1; supplemental material available online with this article; doi:10.1172/ JCI66323DS1). Thus, this transgenic mouse model allows for the identification of the transition period of newly differentiated $\beta$ cells, taking advantage of the rather long half-life of the red fluorescent protein. When a newly differentiating $\beta$ cell (neogene- 


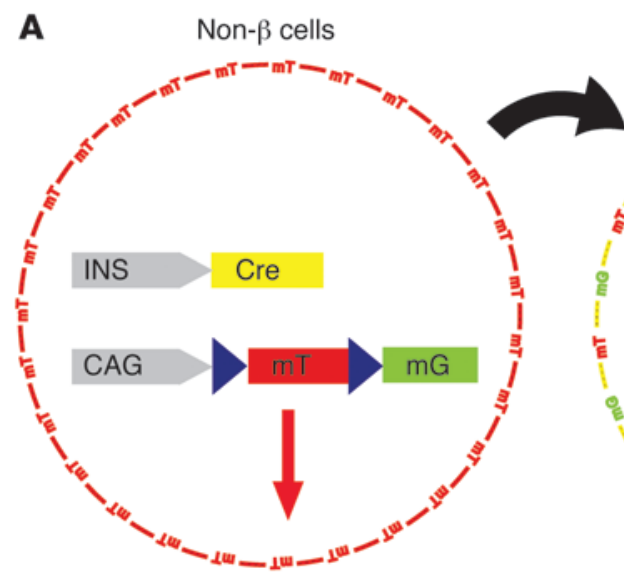

Red cells
Newly differentiated $\beta$ cells

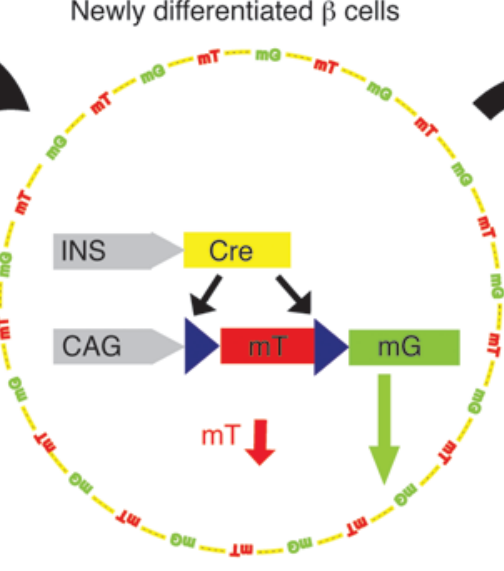

Yellow cells
Differentiated $\beta$ cells

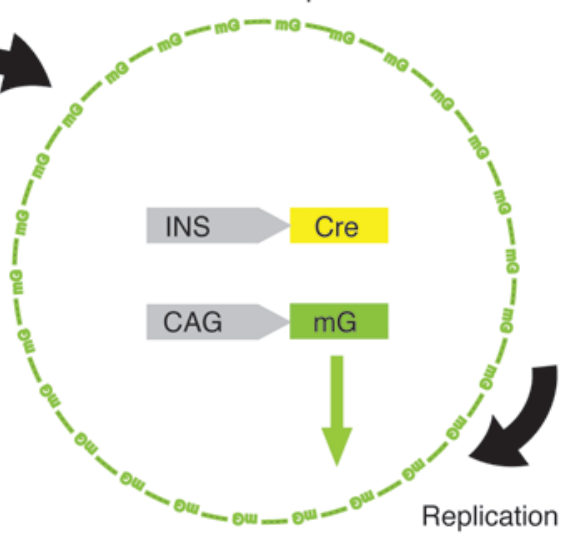

Green cells

B
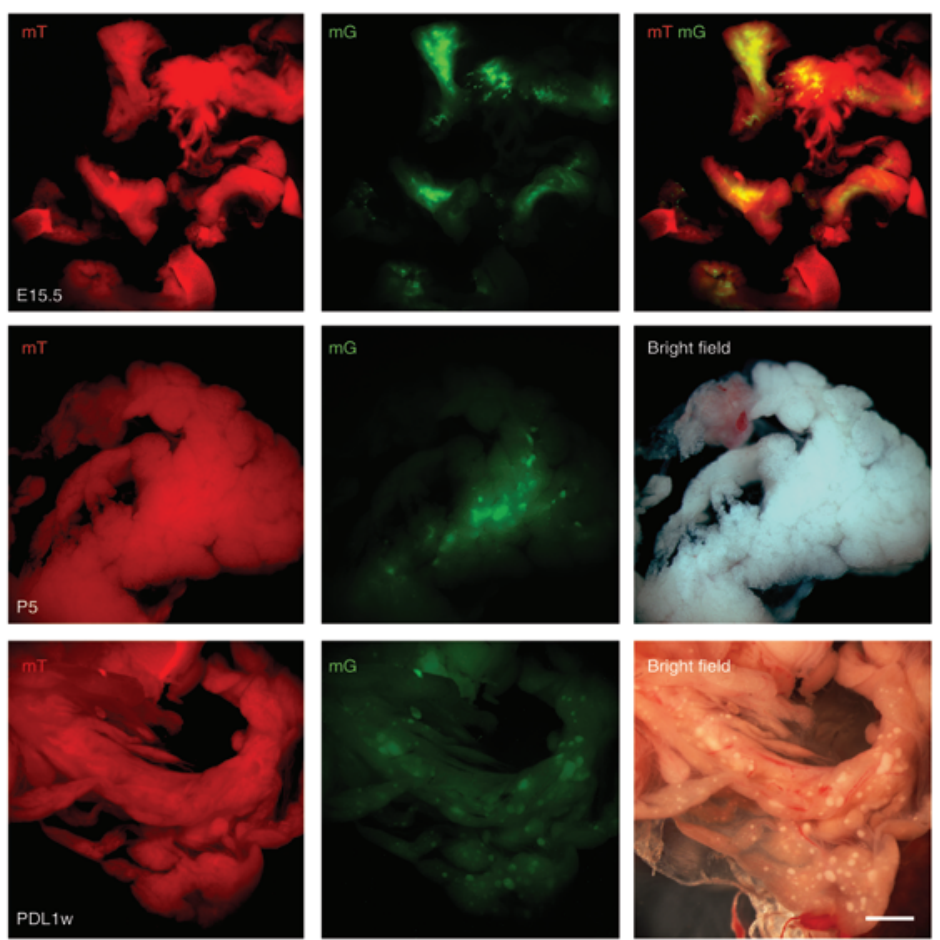

\section{Figure 1}

Generation of INSCremTmG mice for detection of $\beta$ cell neogenesis. (A) Schematic of the INSCremTmG model. In these mice, all cells are mT+ except for the INS ${ }^{+}$cells that are $\mathrm{mG}^{+}$. When non- $\beta \mathrm{mT}^{+}$cells ( $\beta$ cell progenitors) first start to express the insulin promoter, there is a period during which the cells are still $\mathrm{mT}^{+}$, but now express $\mathrm{mG}$, and hence appear yellow $\left(\mathrm{mT}^{+} \mathrm{mG}^{+}\right)$. This model should allow for the detection of any neogenesis scenario in which $\beta$ cells were recently generated from non- $\beta$ cells. Simple replication of preexisting INS ${ }^{+}$cells does not involve a yellow cell stage, as they are already green prior to replication, and over time express the red fluorescent protein. (B) Representative images under a dissecting fluorescence microscope of E15.5, P5 and the ligated tail pancreas 1 week after PDL. Green mG ${ }^{+}$cells can be visualized among the red $\mathrm{mT}^{+}$cells in these conditions. Scale bar: $200 \mu \mathrm{m}$.

sis) starts to translate green fluorescent protein for the first time, the red fluorescent protein on the cell membrane is still present. This transient coexpression of both red and green fluorescent proteins in the same cell makes it appear yellow for a window of time, and thus can be captured by flow cytometry or microscopy. $\beta$ cell proliferation (not neogenesis) does not involve this passage through an intermediate yellow cell stage because the cells had previously become green only. This scheme thus allows us to distin- guish between $\beta$ cell proliferation and neogenesis, with yellow cells in INSCre $\mathrm{mTmG}$ mice representing $\beta$ cell neogenesis (Figure $1 \mathrm{~A}$ ).

We then analyzed whole-pancreas digests from INS ${ }^{\mathrm{Cre}} \mathrm{mTmG}$ mice at different embryonic stages, postnatally, as well as across models of significant $\beta$ cell loss (treatment with alloxan [ALX] or streptozotocin $[\mathrm{STZ}]), \beta$ cell growth and regeneration (50\% partial pancreatectomy [PPX], 75\% PPX, and during pregnancy), and in inflammation (PDL). The relatively translucent nature of the embryonic pancreas, 
A

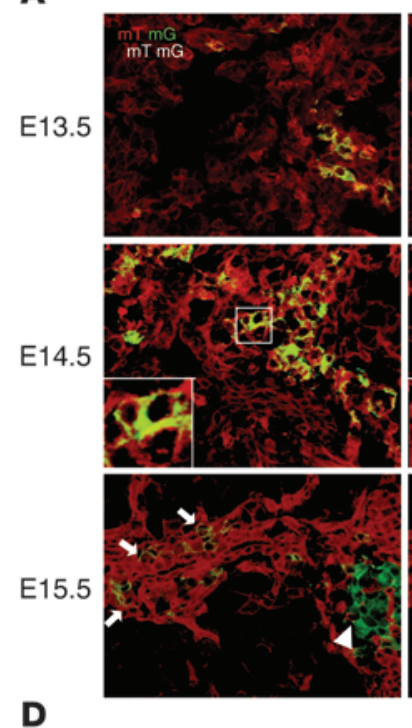

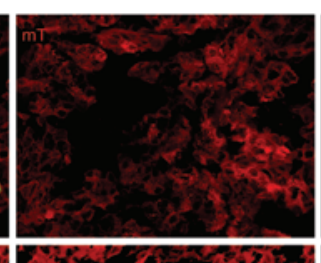
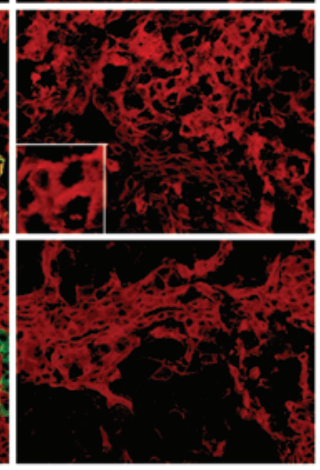
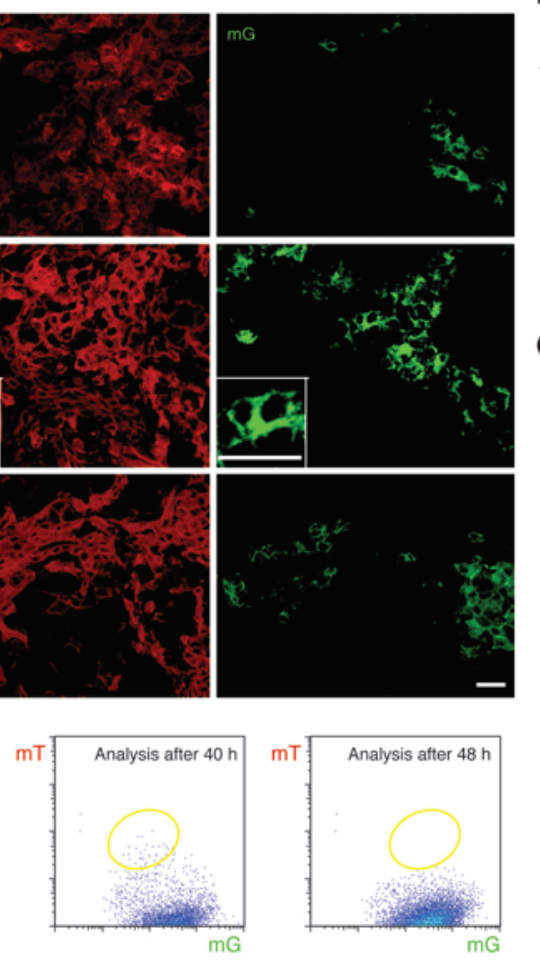

\section{B}

Percentage of yellow and green cells in total yellow + green cells

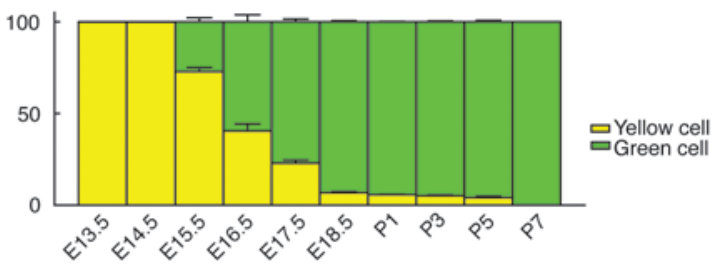

C

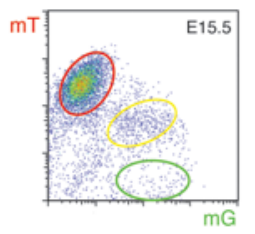

$\mathbf{E}$

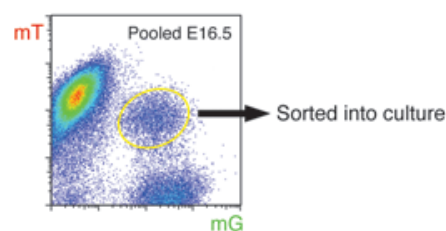

Gene enrichment in sorted cells (normalized to cycloA;

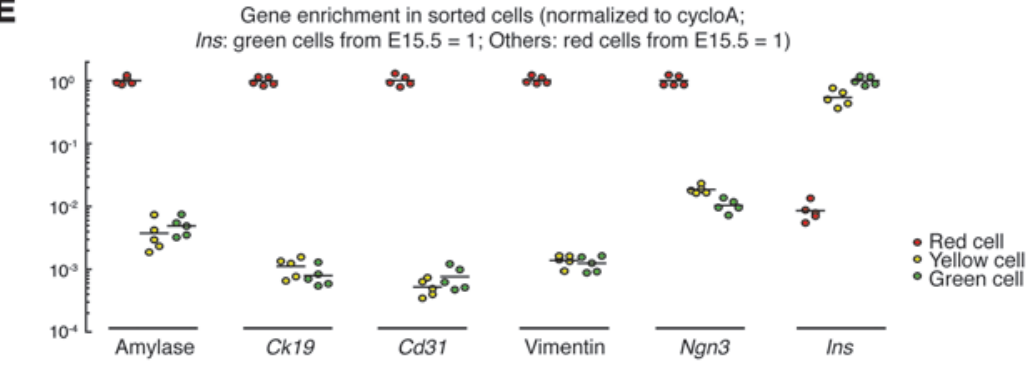

\section{Figure 2}

Validation of the INSCremTmG model. (A) Confocal images of INSCremTmG pancreatic sections show exclusively yellow cells (no green $\mathrm{mT}^{-m G}{ }^{+}$ cells) at E13.5 and E14.5, but both yellow (arrows) and green cells (arrowhead) are visible at E15.5. Inset shows a representative yellow cell at high magnification. (B) Percentages of yellow cells of the total yellow and green cells were quantified at embryonic and early postnatal stages by microscopy, which shows that the initial detection of green cells is approximately 2 days after the initial detection of yellow cells (E15.5 versus E13.5). Yellow cell percentages continuously decreased with time and became undetectable after P5. (C) FACS of E15.5 INSCremTmG pancreatic digests. Red, yellow, and green cell populations are circled red, yellow, and green, respectively, for analysis and sorting. (D) Yellow cells isolated from pooled E16.5 mouse pancreata were cultured. While some cells were reanalyzed immediately by FACS to ensure the absence of red cells, other cells were analyzed at different culture time points. Cultured yellow cells gradually shifted their color to green with time. While a small number of yellow cells could still be detected after 40 hours, none were detected after 48 hours, suggesting that the detection window for yellow cells is 40-48 hours. (E) Gene expression of the red, green, and yellow cells from E15.5 pancreas was analyzed by qPCR. Ngn3 mRNA levels in yellow and green cells are more than 180-fold lower than in red cells. All experiments were performed 5 times. Scale bars: $20 \mu \mathrm{m}$.

the early postnatal pancreas, and the ligated part of the PDL pancreas (due to loss of exocrine tissue) all allow $\mathrm{mG}$ fluorescence to be visualized under dissecting fluorescence microscopy (Figure 1B).

Validation of the model with embryonic INS ${ }^{\mathrm{Cre}} m \mathrm{Tm} G$ pancreas. We needed to determine the time window during which a new $\beta$ cell appears yellow in INS ${ }^{\mathrm{Cre}} \mathrm{mTmG}$ mice by FACS and microscopy. This window of time is related to the time from the onset of expression of $\mathrm{mG}$ to the time of $\mathrm{mT}$ protein decay below detection levels. This time window is an important parameter, as it essentially defines the sensitivity of the system. We compared the INSCre $\mathrm{mTmG}$ embryos across different stages and quantified the ratio of yellow cells to green cells (Figure 2, A-C). Our data show that yellow cells were initially detectable by microscopy at E13.5, but green cells (no red anymore) were only readily detectable by E15.5 (Figure 2, A and B). Since the difference between the initial detection of yellow cells and green cells in the embryonic pancreas should correlate with this time window for yellow cells, our data suggest that the detection window for a yellow cell is between 24 and 48 hours. This microscopic analysis was confirmed by FACS (Figure 2C). Moreover, we found that the ratio of yellow cells to green cells decreases with age (Figure 2B; yellow cell percentage in total yellow and green cells: E13.5: $99.9 \pm 0.2 \%$; E14.5: $99.9 \pm 0.2 \%$; 
A
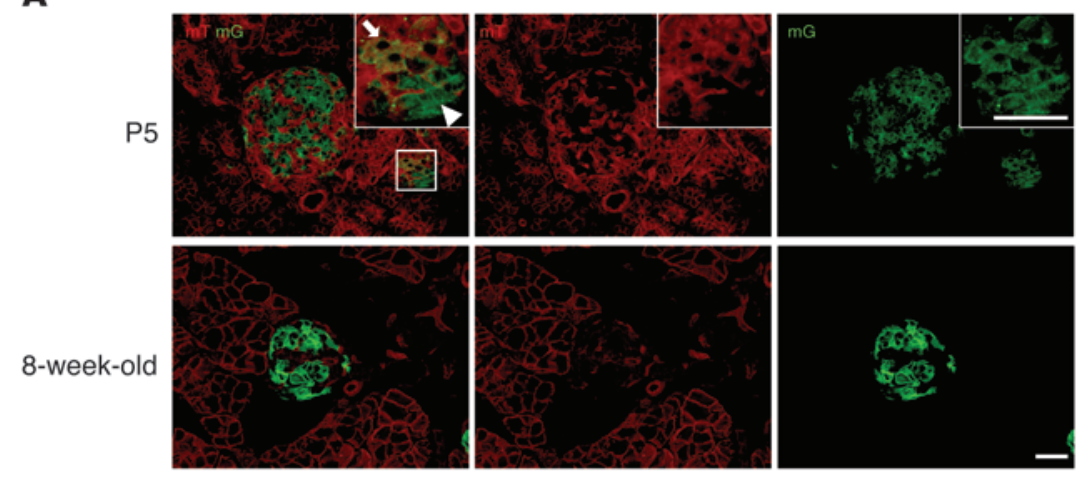

Gene enrichment in sorted cells (normalized to cycloA;

Ngn3: red cells from E15.5 = 1; Ins: green cells from E15.5 = 1)

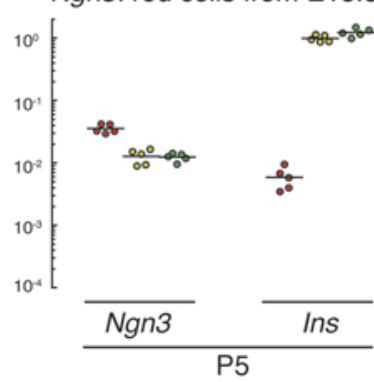

\&००

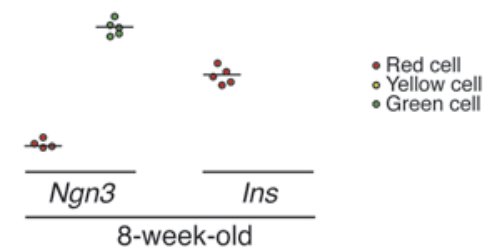

B

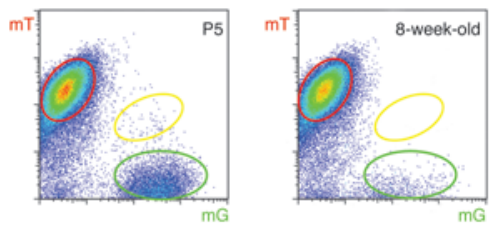

\section{Figure 3}

$\beta$ cell neogenesis is not detected in the pancreas after postnatal day 5. (A) Confocal fluorescence images of cryosections from INSCremTmG mouse pancreas show a few yellow cells (arrow) among the green-only cells (arrowhead) at P5, but no yellow cells at 8 weeks. (B) FACS of pancreatic digests from P5 and 8-week-old INSCremTmG pancreas. While a few yellow cells could be detected at P5, no yellow cells were detected at 8 weeks. (C) Ngn3 mRNA was weakly detected in the red cells isolated from P5, but was not detectable in the red cells isolated from 8-week-old pancreas. The failure to detect yellow cells after P5 (see also Supplemental Figure 3 ) suggests that $\beta$ cell neogenesis does not occur after P5 in the adult pancreas. All experiments were performed 5 times. Scale bars: $20 \mu \mathrm{m}$.

E15.5: $72.9 \pm 2.2 \%$; E16.5: $40.5 \pm 3.8 \%$; E17.5: $23 \pm 1.5 \%$; E18.5: $6.9 \pm$ 0.6\%; P1: $5.7 \pm 0.1 \%$; P3: $5.2 \pm 0.4 \%$; $5: 4.1 \pm 0.8 \%$; $7: 0.07 \pm 0.02 \%$ ) and is consistent with the insulin expression levels in the pancreas (Supplemental Figure 2). To further confirm and narrow down this detection window for yellow cells, we isolated yellow cells from pooled E16.5 mouse pancreas. We chose E16.5 mouse pancreata since they contained the maximum absolute number of yellow cells per pancreas among various embryonic ages in INS ${ }^{\mathrm{Cre}} \mathrm{mTmG}$ mice. The sorted yellow cells were then cultured for different time periods. While 1 group was reanalyzed immediately by FACS to confirm the absence of red cells, the other groups were analyzed $24,32,40,48$, and 56 hours after sorting. We found that yellow cells gradually shifted their color to green with time in culture. A few yellow cells could still be detected after 40 hours, but none were detected after 48 hours (Figure 2D). This result is consistent with the evidence from the in vivo analysis, further narrowing down the detection window for yellow cells to 40 to 48 hours.

We then performed a formal analysis of $\beta$ cell neogenesis during normal development and postnatal growth. Proper compensation was applied before the gates for the 3 populations were set. The FACS gating was then defined by flow cytometry for E15.5 pancreas, and then used as a template for analysis at all of the other ages. Red, yellow, and green cells were sorted and subsequently analyzed for gene enrichment to evaluate the purity of the populations. Theoretically, $\beta$ cells are composed of yellow cells, which are newly differentiated (within 48 hours after the turn-on of insulin), and green cells, which are established $\beta$ cells (48 hours or more after the turn-on of insulin). Red cells represent non- $\beta$ cells in the pancreas, including acinar cells, duct cells, endothelial cells, mesenchymal cells, and low numbers of some other cell types. $\beta$ cell progenitor cells, if present, should be found in the red cell populations. Our data show that the transcript levels for amylase (a marker of acinar cells), Ck19 (a marker of duct cells), Cd31 (a marker of endothelial cells), and vimentin (a marker of mesenchymal cells) are at least 400-fold lower in the yellow and green cells, compared with those in the red cells, while the transcript levels for insulin in the red cells is about 100-fold lower than in the yellow and green cells (Figure 2E). These ratios suggest a high level of purity. Ngn3 mRNA levels in yellow and green cells are more than 180-fold lower than the Ngn3 mRNA levels in red cells, consistent with previous studies showing that NGN3 expression shuts off or dramatically decreases prior to insulin expression (7-9). Here, to make all the models in our study comparable, we used the red cells from E15.5 pancreas to normalize the mRNA levels for amylase, Ck19, Cd31, vimentin, and Ngn3, and we used the green cells from E15.5 pancreas to normalize the mRNA levels for insulin.

$\beta$ cell neogenesis is not detected in the pancreas after postnatal day 5. We then examined the INS ${ }^{\mathrm{Cr}} \mathrm{mTmG}$ pancreas at ages P1, P3, P5, P7, P14, P28, and 8 weeks to determine the presence of yellow cells. By microscopy, we found that yellow cells could only be detected on or before P5 ( $4.1 \pm 0.8 \%$ of total green and yellow cells were yellow at P5, Figure $2 \mathrm{~B}$ and Figure $3 \mathrm{~A}$ ), and essentially could not be detected 
A
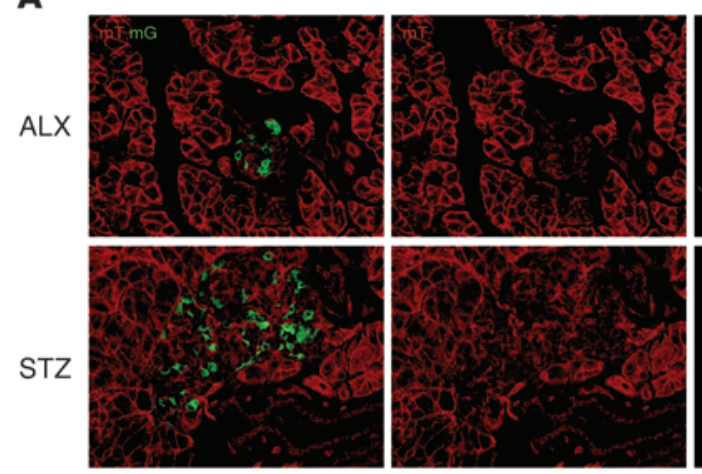

Gene enrichment in sorted cells (normalized to cycloA;

C
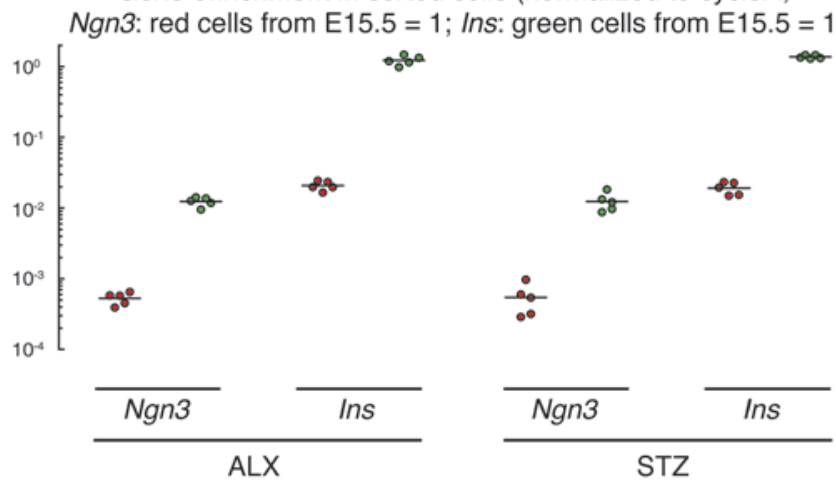

STZ
B
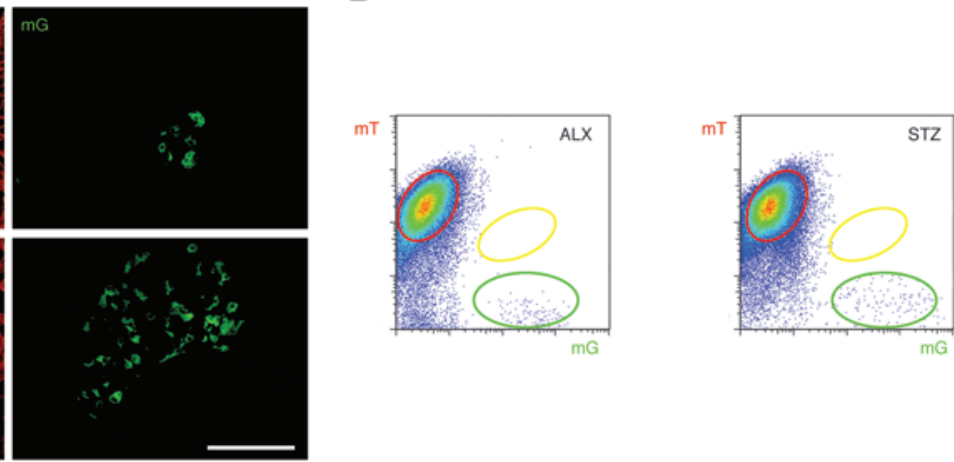

- Red cell
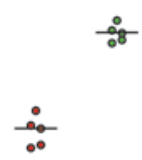

$\stackrel{0}{\circ-0}$

- Green cell

Figure 4

$\beta$ cell neogenesis does not occur after significant $\beta$ cell loss. (A) Confocal fluorescence images of cryosections from INScremTmG pancreas show no yellow cells 1 week after either ALX or STZ treatment. (B) FACS of pancreatic digests from ALX- or STZ-treated mice; no yellow cells can be detected in either condition. (C) Red and green cell fractions were isolated from ALX- or STZ-treated pancreas, and gene expression was analyzed by qPCR. Ngn3 mRNA was essentially undetectable in either red cells or green cells, suggesting that $\beta$ cell neogenesis does not occur after significant $\beta$ cell loss. All experiments were performed 5 times. Scale bar: $50 \mu \mathrm{m}$.

by P7 (Figure 2B; $0.07 \pm 0.02 \%$ of total green and yellow cells were yellow at P7). Representative confocal microscopic images of P5 and 8 -week-old pancreas $(0.03 \pm 0.01 \%$ of total green and yellow cells are yellow at 8 weeks) are shown in Figure 3A, with similar results by FACS shown in Figure 3B. The red, yellow (if present), and green cells were analyzed after FACS. After purity of the cell populations was confirmed by checking mRNA expression for amylase, Ck19, Cd31, and vimentin, we analyzed $N g n 3$ and insulin transcript levels. Ngn3 mRNA was weakly detected in the red cells isolated at P5 (Ngn3 mRNA levels in red cells at P5 were $3.5 \pm 0.2 \%$ of the Ngn3 mRNA levels in red cells from E15.5 pancreas), but not detected afterward (Figure 3C and Supplemental Figure 3). Of note, the levels of Ngn3 mRNA in both yellow and green cell populations from all time points are consistently about $1 \%$ of the $\mathrm{Ngn} 3$ mRNA levels in red cells from E15.5 pancreas (Figure 2E, Figure 3C, and Supplemental Figure 3). These levels of Ngn 3 mRNA in $\beta$ cells (green and yellow cells) are higher than might be expected for cells in an adult pancreas, but are consistent with reports of NGN3 immunostaining in adult $\beta$ cells $(25,33-35)$. Our findings of the absence of yellow cells in the pancreas after P5 suggest that $\beta$ cell neogenesis does not occur after the early postnatal period (36).

$\beta$ cell neogenesis does not occur after significant toxin-induced $\beta$ cell loss. Next, we examined the INS ${ }^{\mathrm{Cre}} \mathrm{mTmG}$ pancreas after treatment with $\beta$ cell-specific toxins, ALX or STZ. By microscopy, yellow cells were essentially undetectable 1 week after either ALX or STZ treatment
(Figure 4A), or by FACS (Figure 4B). Interestingly, analysis of the sorted cells showed that Ngn3 mRNA was not upregulated in the red cells after either treatment (ALX: Ngn3 mRNA levels in red cells were $0.05 \pm 0.005 \%$ of the $\mathrm{Ngn} 3 \mathrm{mRNA}$ levels in red cells from E15.5 pancreas; STZ: $0.05 \pm 0.01 \%$ ), consistent with a lack of neogenesis (Figure 4C). Of note, the analysis of the pancreas 3 days and 4 weeks after these treatments showed similar results. Overall, these data suggest that $\beta$ cell neogenesis does not occur after significant toxin-induced $\beta$ cell loss.

$\beta$ cell neogenesis does not occur during pregnancy or after PPX. We then examined the INS ${ }^{\mathrm{Cre}} \mathrm{mTmG}$ pancreas 3 days, 1 week, and 4 weeks after $50 \%$ or $75 \%$ PPX (only 1-week data are shown) and during pregnancy (E14.5, E15.5, E16.5, and E17.5; only E15.5 data are shown). Yellow cells were essentially undetectable in any of these conditions either by microscopy (Figure 5A), or by FACS (Figure 5B). Again, analysis of the sorted cells showed that $\mathrm{Ngn} 3 \mathrm{mRNA}$ is not upregulated in the red cells in any of the conditions (50\% PPX: Ngn3 mRNA levels in red cells were $0.02 \pm 0.003 \%$ of the $N g n 3$ mRNA levels in red cells from E15.5 pancreas; 75\% PPX: $0.03 \pm 0.004 \%$; Pregnancy: $0.03 \pm 0.006 \%$ ), confirming the findings from microscopy and FACS (Figure 5C). These data suggest that $\beta$ cell neogenesis occurs neither during pregnancy nor after PPX.

$\beta$ cell neogenesis is not detected after PDL. The PDL model has rendered conflicting results with regard to $\beta$ cell neogenesis. In theory, a proper PDL should not affect major pancreatic vessels and 
A
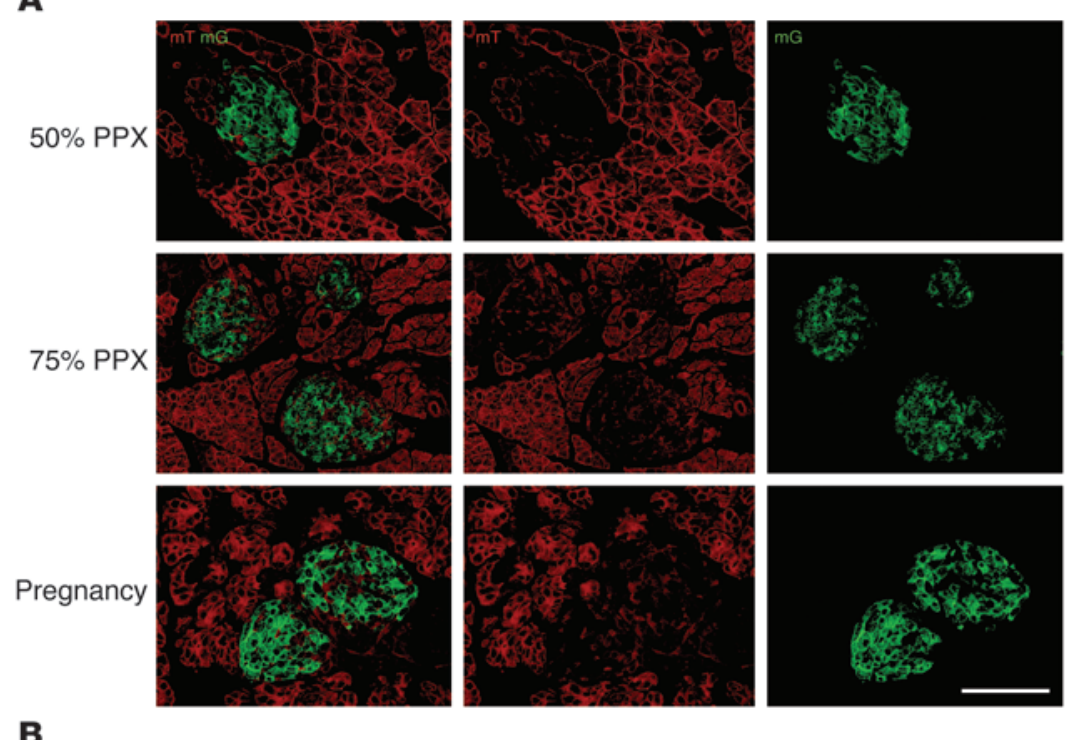

B
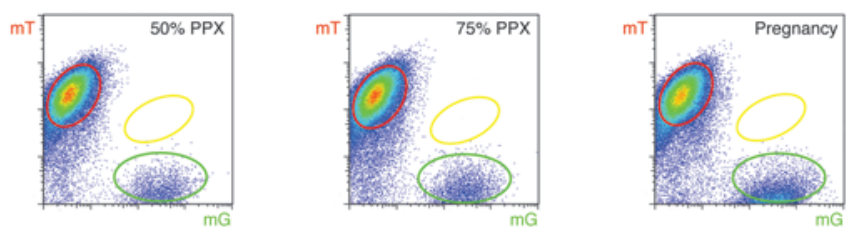

C

Gene enrichment in sorted cells (normalized to cycloA;

Ngn3: red cells from E15.5 = 1; Ins: green cells from E15.5 = 1)

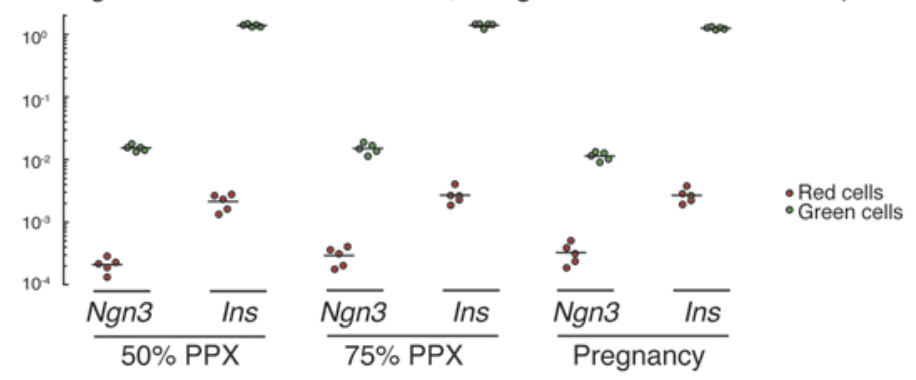

Figure 5

$\beta$ cell neogenesis does not occur during pregnancy or after PPX. (A) Confocal fluorescence images of cryosections from INS CremTmG pancreas show essentially no yellow cells 1 week after either $50 \%$ PPX or $75 \%$ PPX, or during pregnancy (E15.5). (B) FACS of pancreatic digests from $50 \%$ PPX or $75 \%$ PPX, or pregnant mice (E15.5). No yellow cells were detected in any of these conditions. (C) Red and green cell fractions were isolated from $50 \%$ PPX or $75 \%$ PPX, or from pregnant pancreas, and gene expression was analyzed by qPCR. Ngn3 mRNA was essentially undetectable in either red or green cells, suggesting that $\beta$ cell neogenesis does not occur during pregnancy or after PPX. All experiments were performed 5 times. Scale bar: $50 \mu \mathrm{m}$.

should not cause significant tissue necrosis. The exocrine tissue within the ligated tail of the pancreas undergoes severe inflammation, with essentially complete loss of acinar tissue (Figure 6, A-C) $(37,38)$. Therefore, the ligated tail of the PDL pancreas becomes more translucent (see also Figure 1B) within 1 week after PDL due to exocrine atrophy. Here, the islets in the tail can be visualized clearly with the naked eye (Figure 6, A-C). The validity of our PDL model was further confirmed by histology (Figure 6D) and by quantitative PCR (qPCR) showing more than a 100-fold increase in Ngn3 mRNA transcripts in the ligated tail of the pancreas (unsorted), compared with either the nonligated head or untreated control pancreas (Supplemental Figure 4) (38). The nonligated head of the pancreas is an ideal internal control, with no histological differences compared with untreated pancreas (Figure 6, A-C). Yellow cells were not detectable in the ligated tail of the pancreas, either by microscopy (Figure 6D) or by FACS (Figure 6E), suggesting that $\beta$ cell neogenesis does not occur after PDL. Analysis of the sorted cells showed that amylase mRNA levels in red cells from the ligated tail were $1.6 \pm 0.2 \%$ of the amylase mRNA levels in red cells from the nonligated head, suggesting that the majority of acinar cells were destroyed. Ck19 mRNA levels in red cells from the ligated tail were $89.4 \pm 3$.2-fold higher than Ck19 mRNA levels in red cells from the nonligated head, suggesting duct cell enrichment. Ngn3 mRNA was highly upregulated in both red and green cells in the ligated tail of the pancreas (Figure 6F: Ngn3 mRNA levels in red cells were $33 \pm 2 \%$ of the $N g n 3$ mRNA levels in red cells from E15.5 pancreas, or about 1,600-fold higher than the Ngn3 mRNA levels in red cells from the 8-week-old untreated pancreas; green cells: $25 \pm 2 \%$, or about 30 -fold greater than the level of $\mathrm{Ngn} 3 \mathrm{mRNA}$ in green cells from the 8-week-old untreated pancreas). Analysis of the pancreas 3 days and 4 weeks after PDL showed similar results. These data suggest that activation of NGN3 in non $-\beta$ cells in the ligated tail of the pancreas after PDL did not result in $\beta$ cell neogenesis. However, NGN3 appears to also be activated in preexisting $\beta$ cells in the ligated tail of the pancreas after PDL.

NGN3 is significantly upregulated in ducts and $\beta$ cells after PDL. Since we detected upregulation of $\mathrm{Ngn} 3$ transcripts in both red and green cells from the ligated tail of the pancreas after PDL, we then performed immunostaining and examined which cell types among the red cells express NGN3. We screened 6 NGN3 antibodies from various sources. After studying positive controls (embryonic pancreas E15.5; adult duodenum), negative controls, isotype controls, or blocking peptides, we decided to use 2 antibodies that gave reliable and similar results (rabbit anti-mouse NGN3 from Millipore is used for Figure 6). Based on DBA labeling, we found that in the ligated tail of the PDL pancreas, essentially all NGN3 ${ }^{+}$ cells outside of the islets were DBA-positive duct cells, $98.3 \pm 4.6 \%$ of which were INS- (Figure 6G). Since we failed to detect yellow cells here (Figure 6, D and E), it suggests that these $\mathrm{NGN}^{+}$duct cells do not further differentiate into $\beta$ cells, consistent with a previous report (29). In the ligated tail islets, $85.9 \pm 4.3 \%$ of the $\beta$ cells were $\mathrm{NGN}^{+}$. NGN3 could also be detected in $6.4 \pm 0.6 \%$ of the glucagon-expressing $\alpha$ cells and $28.5 \pm 1.3 \%$ of the pancreatic polypeptide (PP) cells, but was barely detectable in the somatostatin-expressing $\Delta$ cells (less than $0.1 \%$ ). Our data thus clearly show that NGN3 is significantly upregulated in both ducts and $\beta$ cells in the ligated tail of the PDL pancreas. However, the $\mathrm{NGN}^{+}$ducts do not appear to give rise to $\beta$ cells. 
A
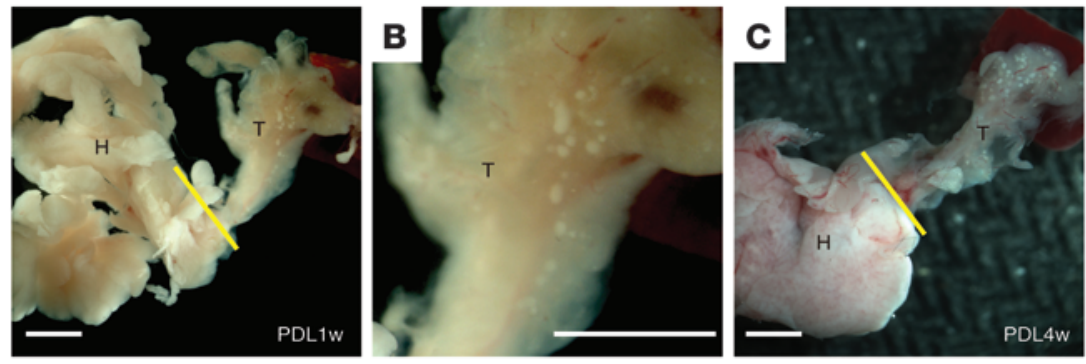

D

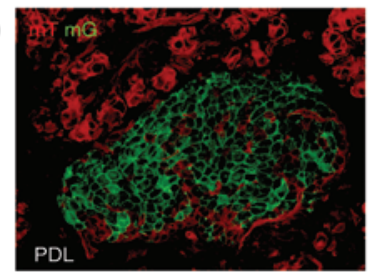

E
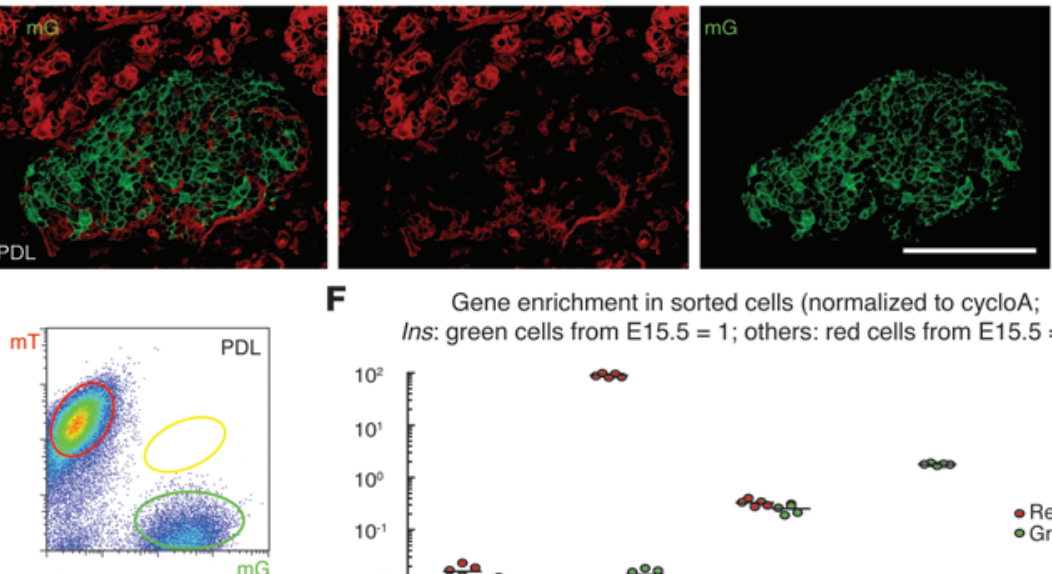

$\mathbf{F}$

Gene enrichment in sorted cells (normalized to cycloA; Ins: green cells from E15.5 = 1 ; others: red cells from E15.5 = 1)

$10^{2}$

\begin{tabular}{c|}
$10^{1}$ \\
$10^{\circ}$ \\
$10^{-1}$
\end{tabular}

$10^{-2}$

$10^{-3}$

$10^{-4}$ Amy

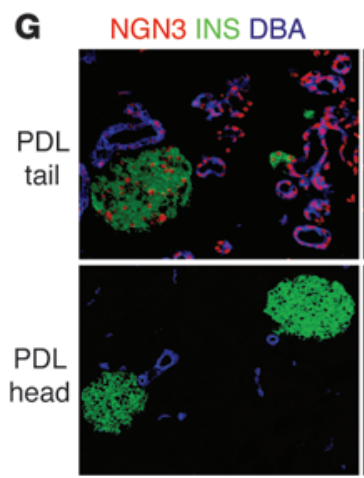

NGN3

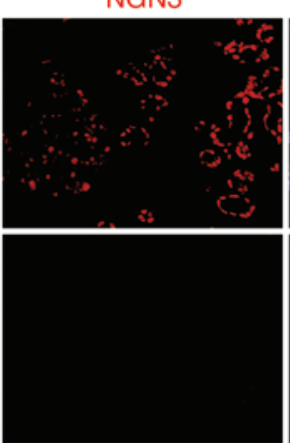

$\infty$
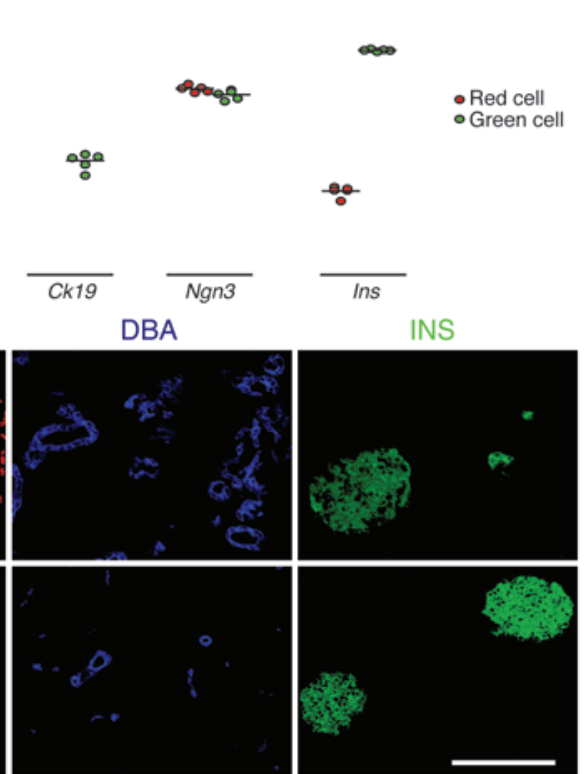

INS

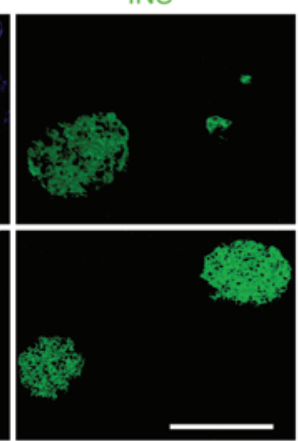

\section{Figure 6}

$\beta$ cell neogenesis does not occur in the PDL pancreas. (A-C) Gross visualization of islets in the ligated tail $(T)$ of the pancreas 1 week ( $\mathbf{A}$ and $\mathbf{B}$ ) and 4 weeks $(\mathbf{C})$ after PDL due to the loss of acini, while the nonligated head $(H)$ of the pancreas appears normal. $\mathbf{B}$ is a magnified view of the tail in A. Ligation position is indicated with a yellow line. (D) Confocal fluorescence images of cryosections from the ligated tail of INSCremTmG pancreas 1 week after PDL. Yellow cells were not detectable. (E) FACS of pancreatic digests from the ligated tail after PDL. Again, no yellow cells could be detected. (F) Gene expression of sorted red and green cells was analyzed by qPCR. Purity of the cells was ensured by checking for the expression of key transcripts. Ngn3 mRNA was highly upregulated in both the red and green cell populations in the ligated tail of the PDL pancreas, suggesting that NGN3 is activated both in non- $\beta$ cells and in preexisting $\beta$ cells after PDL. (G) Triple immunostaining for NGN3 (red), INS (green), and DBA (duct marker, blue) was performed, showing NGN3 positivity in duct cells and islets (mainly $\beta$ cells) in the ligated tail, but not in any cells in the nonligated head of the PDL pancreas. All experiments were performed 5 times. Scale bars: $50 \mu \mathrm{m}$.
Acinar injury and local inflammation can lead to upregulation of $N G N 3$ expression in $\beta$ cells. Finally, we investigated the mechanism underlying the expression of NGN3 in preexisting $\beta$ cells after PDL. We recently showed strong upregulation of proinflammatory genes and influx of inflammatory cells in the ligated tail of the PDL pancreas (38). This local inflammation likely leads to $\beta$ cell replication as a response. The inflammation occurs because PDL blocks the proper drainage of exocrine enzymes via the ductal system, with the presumed leakage of exocrine fluid causing autodigestion and death of acinar cells. The destroyed acinar cells release more digestive enzymes into the parenchyma to further propagate local inflammation. Thus in the PDL model, the potential $\beta$ cell stimuli appear to be the presence of noxious acinar enzymes and proinflammatory mediators. To distinguish the possible effects of these 2 stimuli on $\beta$ cells, we isolated proteins from either normal, unperturbed exocrine cell contents (ducts and acini), presumably devoid of significant amounts of inflammatory factors (e.g., cytokines), or from the ligated tail of the pancreas after PDL, presumably containing both exocrine cell contents and proinflammatory molecules from the PDL milieu. These 2 extracts were cocultured with purified $\beta$ cells from MIP-GFP mice by FACS (37). Reaggregated $\beta$ cells were cultured overnight before exposure to either nucleotide-free normal exocrine extracts, or nucleotide-free PDL tail extracts (representing all PDL stimuli), or control medium for 2 hours (Figure 7A). Then the cells were harvested for RNA extraction followed by qPCR (Figure 7B) or cytospun followed by immunostaining (Figure 7C). Both nucleotide-free exocrine and PDL tail extracts were used as templates to amplify some genes. The absence of PCR products from these extracts confirmed the absence of nucleotide contamination. Amylase, Ck19, Cd31, and vimentin transcripts were also not detected in the $\beta$ cells, confirming the purity of $\beta$ cell sorting by FACS. Ngn3 transcripts were low in $\beta$ cells treated with control medium, but were $17.3 \pm 0.7$-fold 


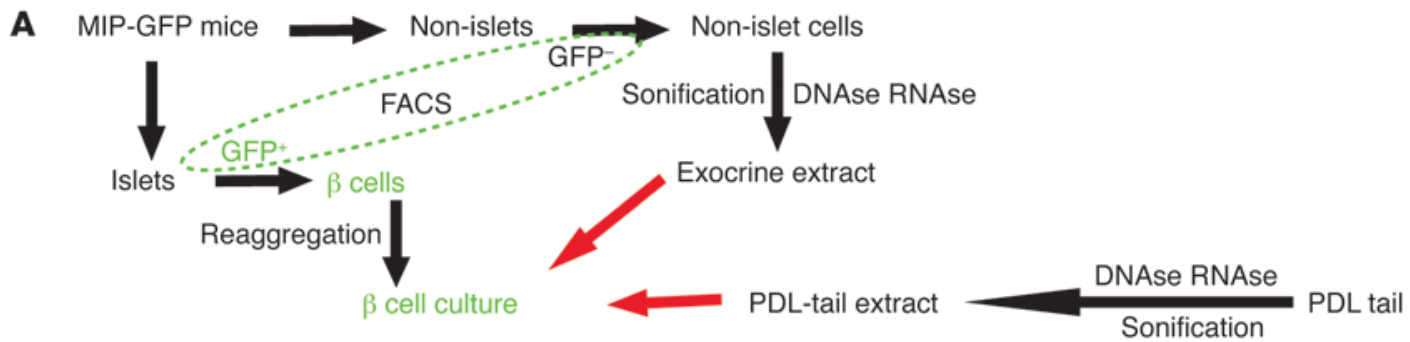

B Gene enrichment in cultured $\beta$ cells (normalized to cycloA;
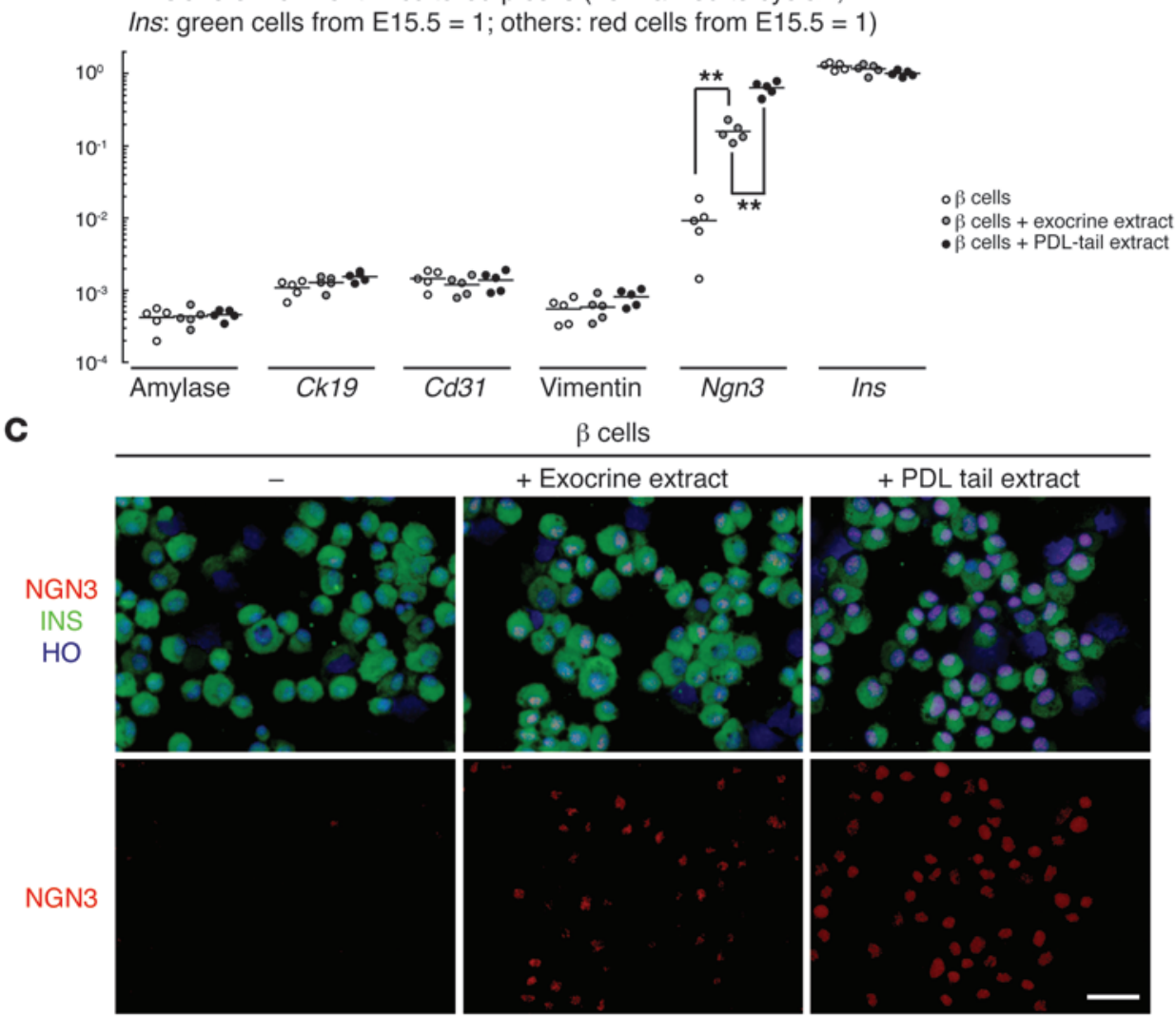

Figure 7

An inflammatory milieu can upregulate NGN3 expression in $\beta$ cells. We hypothesized that the release of acinar cell contents and the inflammatory milieu in the ligated PDL pancreas may induce preexisting $\beta$ cells to upregulate their NGN3 expression. To examine this hypothesis (schematic in A), we isolated purified $\beta$ cells from MIP-GFP mice by FACS. Reaggregated $\beta$ cells were cultured overnight before exposure to nucleotide-free normal exocrine extract (from GFP- cells in MIP-GFP pancreas), or PDL tail extracts, or control medium. After 2 hours' culture, the cells were harvested for RNA extraction and qPCR (B) or cytospun for immunostaining (C). (B) Both nucleotide-free exocrine extract and nucleotide-free PDL tail extracts were used as templates to amplify some genes. The absence of PCR products from these extracts confirmed the absence of nucleotide contamination. Amylase, Ck19, Cd31, and vimentin transcripts were also undetected in the $\beta$ cells, confirming the purity of the MIP-GFP $\beta$ cells by FACS. Ngn3 transcripts were low in $\beta$ cells treated with control medium, but were $17.3 \pm 0.7$-fold upregulated when they were exposed to the exocrine extract for 2 hours, and $68.5 \pm 2$.1-fold upregulated in $\beta$ cells when they were exposed to PDL tail extract for 2 hours. (C) Immunostaining of cytospun cells confirmed the qPCR results. NGN3 in red, insulin in green, and Hoechst (HO) in blue. Scale bar: $20 \mu \mathrm{m} .{ }^{\star \star} P<0.01$.

upregulated when they were exposed to the normal exocrine extract for 2 hours, and $68.5 \pm 2.1$-fold upregulated in $\beta$ cells when they were exposed to the PDL tail extract for 2 hours (Figure 7B). Of note, we found that this NGN3 expression persisted even after the initial insults were removed. These data suggest that the released exocrine cell contents and other inflammatory factors (e.g., cytokines) in the ligated tail of the PDL pancreas induce preexisting $\beta$ cells to upregulate their NGN3 expression and may act synergistically.

\section{Discussion}

The presence of facultative $\beta$ cell progenitors in the adult pancreas has been hotly debated. Although most studies using genetic pulse-chase labeling $(19,27)$, serial thymidine analog labeling (20), and cell lineage tracing (23-26) suggest that $\beta$ cell neogenesis does not occur in the adult pancreas, other reports strongly support such a possibility $(21,22)$.

One of the major concerns with genetic pulse-chase or lineage-tracing studies is the use of a tamoxifen-sensitive Cre system, 
which has been reported to have either prolonged effects (28) or to cause $\beta$ cell prelabeling in young (39) or aged (29) RIPCreERT mice (19). Other newer CreERT strains could potentially suffer from similar flaws related to specificity and sensitivity. Of note, we have found that injection of a single, low dose of tamoxifen can change the promoter activities of a few specific genes, independent of CreERT (Supplemental Figure 5A). Similarly, we found that PDL-induced inflammation could alter numerous gene promoters (Supplemental Figure 5B). Thus, rigorous quality controls need to be applied to such lineage-tracing studies.

Another controversial issue with regard to the PDL model is whether the activation of NGN3, a key determinant of endocrine cell neogenesis during embryonic development (7-9), represents $\beta$ cell neogenesis. NGN3 has long been regarded as a signature for $\beta$ cell neogenesis, but recent reports showed that adult $\beta$ cells express a low level of NGN3 $(25,33-35)$.

Here, we used a tamoxifen-independent Cre model to detect $\beta$ cell neogenesis, taking advantage of the relatively long half-life of the red reporter in newly differentiated $\beta$ cells in INSCre $\mathrm{mTmG}$ mice (40-42). First, we defined the detection window for a neonatal $\beta$ cell as lasting 40 to 48 hours, suggesting that this model is sensitive enough to analyze $\beta$ cell neogenesis in most circumstances. We then checked for the presence of $\beta$ cell neogenesis during different stages of pancreatic development and across multiple well-established models of significant $\beta$ cell loss, $\beta$ cell growth and regeneration, and inflammation (PDL). We believe that it is important to use FACS detection, rather than just microscopy alone, because the former is highly objective and allows for rapid and efficient analysis of an entire pancreas. Our data provide strong evidence against the presence of $\beta$ cell neogenesis in the adult pancreas, as we detected no yellow cells (positive for both red and green reporters) there. In order to exclude the possibility, though unlikely (40-47), that $\beta$ cell replication immediately following neogenesis may dilute out the red color and prevent the detection of yellow cells, we performed BrdU pulse experiments and found that proliferating and recently proliferated yellow cells can be readily detected (Supplemental Figure 6).

NGN3 expression in established $\beta$ cells can be detected with a highly sensitive immunostaining system, using an amplification step $(25,33-35)$. We now further show that NGN3 expression in $\beta$ cells can be significantly increased in response to the harsh milieu of PDL. In addition, we found that $\beta$ cell expression of other key transcription factors was also affected by PDL. For example, Pax 4 and Ptf1a were modestly, but prolongedly, upregulated in some $\beta$ cells (Supplemental Figure 5B). These changes may indicate de-differentiation of $\beta$ cells to a certain degree in response to local insults, which may be an adaptation to somehow improve $\beta$ cell survival and to increase proliferation, as shown by recent reports $(48,49)$. Importantly, prolonged upregulation of Ptfla may create problems when using Ptfla $a^{C r E R T}$ mice for lineage tracing of adult acinar cells, since Ptfla is regarded as acinar cell specific in the adult pancreas. Here, modest but prolonged upregulation of cytoplasmic Cre recombinase could result in leaky labeling of these $\beta$ cells.

PDL was previously reported to lead to a doubling in $\beta$ cell mass within 1 week (21). Although $\beta$ cell proliferation increases approximately 10 -fold after PDL $(21,38)$, the absolute level is still relatively low. Indeed, we previously provided mice with BrdU in their drinking water to continuously label all proliferating cells over the first week after PDL and found that only $12 \%$ of $\beta$ cells were $\mathrm{BrdU}^{+}$ (38). Therefore, if $\beta$ cell mass had truly doubled within 7 days after
PDL, then most $\beta$ cells would have had to derive from neogenesis. It is thus not possible for all of these newly differentiated $\beta$ cells to escape detection in our INSCremTmG model. Importantly, it was also reported that little $\beta$ cell apoptosis was detected within 1 month of PDL (21). Moreover, a recent report found that there is no change in $\beta$ cell numbers after PDL (50). Thus, if $\beta$ cell mass did indeed double, then individual $\beta$ cells would have to significantly increase their size and volume, which does not appear to be the case in any PDL studies. Indeed, severe tissue edema and tissue remodeling occur after PDL, which can lead to a significant overestimation of $\beta$ cell mass when calculated as a product of $\beta$ cell area and pancreas weight (25). Thus, analyzing $\beta$ cell mass this way may not be a proper method in PDL. Collectively, it appears that there is strong evidence against $\beta$ cell neogenesis in PDL (21).

Our study provides strong evidence for explaining the discrepancy among 6 different previous lineage-tracing reports in the PDL model $(22-26,51)$. We show that NGN3 expression occurs not only in the exocrine portion of the ligated pancreas, but also in preexisting $\beta$ cells. $\mathrm{NGN3}^{+}$cells in ducts, however, do not appear to give rise to $\beta$ cells, consistent with a previous report (29). Thus, NGN3 may not be an ideal marker for the identification of $\beta$ cell progenitors in adults. Although our data strongly suggest that $\mathrm{NGN}^{+}$ducts in a ligated pancreas do not contribute to $\beta$ cell expansion in vivo, it does not rule out the possibility that such ductal NGN3 ${ }^{+}$cells could differentiate into $\beta$ cells if transplanted into an embryonic pancreas explant, as previously described (21). In those types of experiments, however, a marker other than NGN3 may be necessary to guide the isolation of putative progenitor cells to prevent contamination with preexisting $\beta$ cells.

Although INS ${ }^{\mathrm{Cre}} \mathrm{mTmG}$ appears to be a very sensitive and reliable model for detecting $\beta$ cell neogenesis, it is probably not suitable for detecting the $\beta$ cell neogenesis that may occur slowly over a long period (52).

Although we only used this system to detect $\beta$ cell neogenesis, it should be applicable to other fields, such as stem cell research, for examining cell differentiation and especially for distinguishing cell replication from neogenesis.

\section{Methods}

Mouse manipulation. C57/6, MIP-GFP (53), insulin promoter Cre reporter $\left(\right.$ Ins $\left.{ }^{\mathrm{Cr}}\right)$ (31), and ROSA $\mathrm{mTmG}(\mathrm{mTmG})(32)$ mice were all purchased from The Jackson Laboratory and have the same C57/6 background. The latter 2 were crossed to generate the INS ${ }^{\mathrm{Cre}} ; \mathrm{mTmG}$ (INS $\left.{ }^{\mathrm{Cre}} \mathrm{mTmG}\right)$ strain. Only mice that were heterozygous for both Cre and $\mathrm{mTmG}$ were used for our experiments. All experiments for adults used 8-week-old females. The $\beta$ cell toxin ALX (65 mg/kg body weight) was injected into the mice via the dorsal tail vein, while STZ (150 mg/ $\mathrm{kg}$ body weight) was injected intraperitoneally. BrdU pulse labeling was done by a single intraperitoneal injection of $50 \mathrm{mg} / \mathrm{kg}$ BrdU into pregnant mice 6 hours prior to harvest. Blood glucose measurements of mice across various models were performed after a 2-hour fasting period and confirmed the presence or absence of the effects of the interventions on blood glucose (Supplemental Figure 7). PPX and PDL were performed as described (38). The percentage of PPX was controlled by comparing the weight of the excised pancreatectomy specimen with the average weight of the total pancreas from mice of the same litter. PDL quality was ensured by examining NGN3 transcription in isolated cells and unsorted ligated tail pancreas (Figure 6E and Supplemental Figure 4), gross morphology (Figure 1B and Figure 6A), NGN3 immunostaining (Figure 6F), and by comparing these with both the nonligated tail of the pancreas in PDL and the untreated mice (38). 
Pancreatic digestion and FACS. Pancreatic ductal perfusion and subsequent digestion of the pancreas was performed with $0.2 \mathrm{mg} / \mathrm{ml}$ collagenase. If islets were needed, they were sequentially hand-picked 3 times to avoid contamination with non-islet cells. The purity of the islets was confirmed by the absence of amylase and CK19 transcripts in the RNA samples extracted from the isolated islets. If single-cell populations were needed for FACS, further digestion of islets or pancreatic digests was performed with $10 \mu \mathrm{g} / \mathrm{ml}$ trypsin (Sigma-Aldrich) and $10 \mu \mathrm{g} / \mathrm{ml}$ DNase (Roche) after collagenase treatment. After filtration at $30 \mu \mathrm{m}$, the single-cell populations from INS ${ }^{\mathrm{Cre}} \mathrm{mTmG}$ mice were sorted on a FACSAria cell sorter (BD Biosciences) to isolate red, green, and yellow fluorescent cells, and those from MIP-GFP mice were sorted to isolate $\mathrm{GFP}^{+}$and GFP- cells, respectively, based on fluorescence. Since spectral overlap between FITC and PE produces light detected by both the FL1 and FL2 detectors, the amount of FITC fluorescence being detected by the FL2 detector for INS ${ }^{\mathrm{Cre}} \mathrm{mTmG}$ pancreatic digests was regarded as excess fluorescence and was compensated out to clearly show the different cell populations. Flow cytometry data were analyzed using FlowJo software (Tree Star). The purity of $\beta$ cells from MIP-GFP mice was confirmed by the absence of amylase, CK19, CD31, vimentin, and other endocrine hormone (glucagon, somotostain, and PP) transcripts in the RNA. The purity of the sorted red, yellow, and green cell fractions from INS ${ }^{\mathrm{Cre}} \mathrm{mTmG}$ mice was evaluated by the expression of cell type-specific markers with quantitative qPCR. The exocrine extract was prepared using the GFP- non-islet fractions from MIP-GFP mice, while the PDL tail extract was prepared using homogenized, ligated PDL tail pancreas from C57/6 mice. The sorted GFP- cells or ligated tail pancreas tissue were ultrasonicated and DNAse and RNAse treated before centrifugation to remove surviving cells and debris. The supernatant was isolated and used as an insult to $\beta$ cells, representing exocrine cell content or PDL tail extract, respectively, and proved to be nucleotide-free by qPCR.

Cell culture. Isolated $\mathrm{GFP}^{+} \beta$ cells were reaggregated and cultured overnight in a 24-well plate with Ham's F10 medium (Life Technologies) supplemented with $0.5 \%$ BSA (Sigma-Aldrich), $2 \mathrm{mM}$ glutamine, $2 \mathrm{mM}$ calcium, and $5 \mathrm{mM}$ glucose $\left(37^{\circ} \mathrm{C}, 5 \% \mathrm{CO}_{2}\right)(37)$. Thereafter, the $\mathrm{GFP}^{+}$ $\beta$ cells were supplied with fresh medium and either exocrine extract or PDL tail extract for a 2-hour period. The cells were then harvested for RNA extraction to examine gene transcription and were cytospun for immunostaining.

RNA isolation and RT-qPCR. RNA was extracted from pancreatic tissue with TRIzol (Invitrogen) and from FACS-sorted cells using the RNeasy mini kit (QIAGEN). RNA quantification was done using NanoDrop 1000 (Thermo Scientific) according to the manufacturer's instructions, followed by cDNA synthesis (QIAGEN). Quantitative PCR primers were all purchased from QIAGEN; they are: CycloA (QT00247709); Ngn3 (QT00262850); insulin (QT00114289); amylase (QT00179242); Ck19 (QT00156667); Cd31 (QT01052044); vimentin (QT00159670); glucagon (QT00124033); somatostatin (QT01046528); PP (QT00103999); Hnf1b (QT00103320); Pax4 (QT01052772); and Ptf1a (QT00124187). qPCR reactions were performed in triplicate with the QuantiTect SYBR Green PCR kit (QIAGEN) using a LightCycler 1.5 instrument (Roche). Specificity of the amplified products was determined by melting peak analysis. Quantification for each gene of interest was performed using the $2^{-\Delta \Delta \mathrm{Ct}}$ method. Values of genes were normalized against CycloA, which proved to be stable across the samples.

1. Pipeleers $D$, et al. A view on $\beta$ cell transplantation in diabetes. Ann NY Acad Sci. 2002;958:69-76.

2. Zaret KS, Grompe M. Generation and regeneration of cells of the liver and pancreas. Science. 2008; 322(5907):1490-1494.

3. Ackermann AM, Gannon M. Molecular regulation of pancreatic beta-cell mass development, main-
Immunohistochemistry. All pancreas samples were fixed in zinc (BD Biosciences) for 4 hours before an additional 2 hours' fixation in $4 \%$ formalin, then cryoprotected in $30 \%$ sucrose overnight before freezing. $\mathrm{mT}$ and $\mathrm{mG}$ were detected by direct fluorescence. Cytospun cells were fixed for 2 hours in $4 \%$ formalin before staining. The primary antibodies for immunostaining were: guinea pig polyclonal insulin and pancreatic polypeptide specific (Dako); rat polyclonal CD31 specific (BD Biosciences) and BrdU specific (Abcam); goat polyclonal insulin specific and Ki-67 specific (Santa Cruz Biotechnology); mouse monoclonal glucagon specific (Sigma-Aldrich) and NGN3-specific (Hybridoma Bank); rabbit polyclonal somatostatin specific (Dako), glucagon specific, Ki-67 specific (Cell Signaling Technology), NGN3 specific (Millipore), and Biotin-DBA (Vector Laboratories). No antigen retrieval was necessary for these antigens except for mouse NGN3 antibody, which requires antigen retrieval and combination with biotin-streptavidin TSA amplification, and for Ki-67 and BrdU, which was demonstrated previously (38). The secondary antibodies for indirect fluorescence staining were: $\mathrm{Cy} 2$, Сy3, or Cy5 conjugated donkey streptavidin, anti-rabbit, antirat, anti-mouse, anti-goat, and anti-guinea pig (Jackson ImmunoResearch Laboratories). Nuclear staining was performed with Hoechst solution (BD Biosciences). Cryosection imaging was performed using either an Olympus Fluo View 1000 confocal microscope under a $\times 40$ oil immersion objective with standard filter sets, or an AxioImager Z.1 microscope (Zeiss) with image analysis using AxioVision software (Zeiss). Gross section images were obtained using an Olympus SZX12 stereomicroscope and captured with SPOT imaging software (SPOT Imaging Solutions).

Statistics. All values are depicted as the mean \pm SEM. At least 10 embryos per time point were analyzed ( 5 for microscopy and 5 for FACS). Only 8-week-old female INS ${ }^{\mathrm{Cre}} \mathrm{mTmG}$ mice were used for the adult experiments, except for pregnancy, in which the age of the mice varied from 10 weeks to 14 weeks. Adult mice were analyzed at 3 days, 1 week, and 4 weeks after treatment. In each group and time point, 5 mice were used for microscopy and 5 for FACS. All qPCR data are from 5 samples for each condition. All data were statistically analyzed by a 2 -tailed Student's $t$ test. A $P$ value less than 0.05 was considered significant.

Study approval. All mouse experiments were approved by the Animal Research and Care Committee guidelines of Children's Hospital of Pittsburgh and the IACUC of the University of Pittsburgh.

\section{Acknowledgments}

Special thanks to Alexis J. Styche, Robert J. Lakomy, and Lauren Brink for technical assistance in flow cytometry and mouse genotyping. Thanks to Christine Kalinyak, Anne L. Meinert, Tamara Daviston, and JoAnn Stiles for administrative assistance. Financial support was provided by the NIH (RO1 DK064952, R01 DK08354101; to G.K. Gittes) and Children's Hospital of Pittsburgh.

Received for publication November 20, 2012, and accepted in revised form January 31, 2013.

Address correspondence to: George K. Gittes, Division of Pediatric Surgery, Children's Hospital of Pittsburgh, University of Pittsburgh School of Medicine, 4401 Penn Ave., Pittsburgh, Pennsylvania 15224, USA. Phone: 412.692.7291; Fax: 412.692.3466; E-mail: gittesgk@upmc.edu. cells into insulin-secreting cells. J Clin Invest. 1996; 97(7):1647-1654

6. Desai BM, et al. Preexisting pancreatic acinar cells contribute to acinar cell, but not islet $\beta$ cell, regeneration. J Clin Invest. 2007;117(4):971-977.

7. Jensen J, et al. Independent development of pancreatic alpha- and beta-cells from neurogenin3- 
expressing precursors: a role for the notch pathway in repression of premature differentiation. Diabetes. 2000;49(2):163-176.

8. Gu G, Dubauskaite J, Melton DA. Direct evidence for the pancreatic lineage: $\mathrm{NGN}^{+}$cells are islet progenitors and are distinct from duct progenitors. Development. 2002;129(10):2447-2457.

9. Schwitzgebel VM, et al. Expression of neurogenin3 reveals an islet cell precursor population in the pancreas. Development. 2000;127(16):3533-3542.

10. Gittes GK. Developmental biology of the pancreas: a comprehensive review. Dev Biol. 2009;326(1):4-35.

11. Murtaugh LC, Melton DA. Genes, signals, and lineages in pancreas development. Annu Rev Cell Dev Biol. 2003;19:71-89.

12. Pan FC, Wright C. Pancreas organogenesis: from bud to plexus to gland. Dev Dyn. 2011;240(3):530-565.

13. Oliver-Krasinski JM, Stoffers DA. On the origin of the $\beta$ cell. Genes Dev. 2008;22(15):1998-2021.

14. Servitja JM, Ferrer J. Transcriptional networks controlling pancreatic development and $\beta$ cell function. Diabetologia. 2004;47(4):597-613.

15. Wilson ME, Scheel D, German MS. Gene expression cascades in pancreatic development. Mech Dev . 2003;120(1):65-80.

16. Edlund H. Pancreatic organogenesis - developmental mechanisms and implications for therapy. Nat Rev Genet. 2002;3(7):524-532.

17. Kopp JL, Dubois CL, Hao E, Thorel F, Herrera PL, Sander M. Progenitor cell domains in the developing and adult pancreas. Cell Cycle. 2011; 10(12):1921-1927.

18. Bonner-Weir $S$, et al. The pancreatic ductal epithelium serves as a potential pool of progenitor cells. Pediatr Diabetes. 2004;5(suppl 2):16-22.

19. Dor Y, Brown J, Martinez OI, Melton DA. Adult pancreatic beta-cells are formed by self-duplication rather than stem-cell differentiation. Nature. 2004; 429(6987):41-46.

20. Teta M, Rankin MM, Long SY, Stein GM, Kushner JA. Growth and regeneration of adult $\beta$ cells does not involve specialized progenitors. Dev Cell. 2007; 12(5):817-826.

21. Xu X, et al. Beta cells can be generated from endogenous progenitors in injured adult mouse pancreas. Cell. 2008;132(2):197-207.

22. Inada $A$, et al. Carbonic anhydrase II-positive pancreatic cells are progenitors for both endocrine and exocrine pancreas after birth. Proc Natl Acad Sci US A. 2008;105(50):19915-19919.

23. Solar M, et al. Pancreatic exocrine duct cells give rise to insulin-producing $\beta$ cells during embryogenesis but not after birth. Dev Cell. 2009;17(6):849-860

24. Furuyama K, et al. Continuous cell supply from a Sox9-expressing progenitor zone in adult liver, exocrine pancreas and intestine. Nat Genet. 2011; 43(1):34-41.

25. Kopp JL, et al. Sox $9^{+}$ductal cells are multipotent progenitors throughout development but do not produce new endocrine cells in the normal or injured adult pancreas. Development. 2011; 138(4):653-665.

26. Kopinke D, Brailsford M, Shea JE, Leavitt R, Scaife CL, Murtaugh LC. Lineage tracing reveals the dynamic contribution of Hes $1^{+}$cells to the developing and adult pancreas. Development. 2011; 138(3):431-441.

27. Nir T, Melton DA, Dor Y. Recovery from diabetes in mice by $\beta$ cell regeneration. J Clin Invest. 2007; 117(9):2553-2561.

28. Reinert RB, et al. Tamoxifen-induced Cre-loxP recombination is prolonged in pancreatic islets of adult mice. PLoS One. 2012;7(3):e33529.

29. Blaine SA, Ray KC, Anunobi R, Gannon MA, Washington $\mathrm{MK}$, Means AL. Adult pancreatic acinar cells give rise to ducts but not endocrine cells in response to growth factor signaling. Development. 2010;137(14):2289-2296.

30. Kasahara T, Hashiba M, Harada T, Degawa M. Change in the gene expression of hepatic tamoxifen-metabolizing enzymes during the process of tamoxifen-induced hepatocarcinogenesis in female rats. Carcinogenesis. 2002;23(3):491-498.

31. Postic $\mathrm{C}$, et al. Dual roles for glucokinase in glucose homeostasis as determined by liver and pancreatic $\beta$ cell-specific gene knock-outs using Cre recombinase. J Biol Chem. 1999;274(1):305-315.

32. Muzumdar MD, Tasic B, Miyamichi K, Li L, Luo L. A global double-fluorescent Cre reporter mouse. Genesis. 2007;45(9):593-605.

33. Wang S, et al. Sustained Neurog3 expression in hormone-expressing islet cells is required for endocrine maturation and function. Proc Natl Acad Sci U S A. 2009;106(24):9715-9720.

34. Dror V, Nguyen V, Walia P, Kalynyak TB, Hill JA, Johnson JD. Notch signalling suppresses apoptosis in adult human and mouse pancreatic islet cells. Diabetologia. 2007;50(12):2504-2515.

35. Jenny $M$, et al. Neurogenin3 is differentially required for endocrine cell fate specification in the intestinal and gastric epithelium. EMBO J. 2002; 21(23):6338-6347.

36. Nakamura K, Minami K, Tamura K, Iemoto K, Miki T, Seino S. Pancreatic beta-cells are generated by neogenesis from non-beta-cells after birth. Biomed Res. 2011;32(2):167-174.

37. Xiao X, et al. Hypoglycemia reduces vascular endothelial growth factor a production by pancreatic beta cells as a regulator of beta cell mass. J Biol Chem. 2013;288(12):8636-8646.
38. Xiao X, et al. TGF $\beta$ receptor signaling is essential for inflammation-induced but not $\beta$-cell workload-induced $\beta$-cell proliferation. Diabetes. 2013; 62(4):1217-1226.

39. Liu Y, et al. Tamoxifen-independent recombination in the RIP-CreER mouse. PLoS One. 2010; 5(10):e13533.

40. Miyatsuka T, Li Z, German MS. Chronology of islet differentiation revealed by temporal cell labeling. Diabetes. 2009;58(8):1863-1868.

41. Sugiyama T, Rodriguez RT, McLean GW, Kim SK. Conserved markers of fetal pancreatic epithelium permit prospective isolation of islet progenitor cells by FACS. Proc Natl Acad Sci U S A. 2007; 104(1):175-180

42. Gu G, Wells JM, Dombkowski D, Preffer F, Aronow $\mathrm{B}$, Melton DA. Global expression analysis of gene regulatory pathways during endocrine pancreatic development. Development. 2004;131(1):165-179.

43. Desgraz R, Herrera PL. Pancreatic neurogenin 3 -expressing cells are unipotent islet precursors. Development. 2009;136(21):3567-3574.

44. Georgia S, Bhushan A. $\beta$ cell replication is the primary mechanism for maintaining postnatal $\beta$ cell mass. J Clin Invest. 2004;114(7):963-968.

45. Georgia S, Bhushan A. p27 Regulates the transition of beta-cells from quiescence to proliferation. Diabetes. 2006;55(11):2950-2956.

46. Hellerstrom C, Swenne I. Functional maturation and proliferation of fetal pancreatic $\beta$-cells. Diabetes. 1991;40(suppl 2):89-93.

47. Swenne I. Pancreatic beta-cell growth and diabetes mellitus. Diabetologia. 1992;35(3):193-201.

48. Talchai C, Xuan S, Lin HV, Sussel L, Accili D. Pancreatic $\beta$ cell dedifferentiation as a mechanism of diabetic $\beta$ cell failure. Cell. 2012;150(6):1223-1234.

49. Negi S, Jetha A, Aikin R, Hasilo C, Sladek R, Paraskevas S. Analysis of beta-cell gene expression reveals inflammatory signaling and evidence of dedifferentiation following human islet isolation and culture. PLoS One. 2012;7(1):e30415.

50. Chintinne M, Stange G, Denys B, Ling Z, In 't Veld P, Pipeleers D. $\beta$ cell count instead of $\beta$ cell mass to assess and localize growth in $\beta$ cell population following pancreatic duct ligation in mice. PLoS One. 2012;7(8):e43959.

51. Chung CH, Hao E, Piran R, Keinan E, Levine F. Pancreatic $\beta$-cell neogenesis by direct conversion from mature $\alpha$-cells. Stem Cells. 2010;28(9):1630-1638.

52 . Thorel F, et al. Conversion of adult pancreatic $\alpha$-cells to $\beta$-cells after extreme $\beta$-cell loss. Nature. 2010;464(7292):1149-1154.

53 . Hara $\mathrm{M}$, et al. Transgenic mice with green fluorescent protein-labeled pancreatic $\beta$-cells. Am J Physiol Endocrinol Metab. 2003;284(1):E177-E183. 